years. The mean disease duration was $12.65 \pm 9.49$ years. The clinical presentation of SpA was peripheral in 61 cases and axial in 118 cases. The mean disease scores activity was: BASDAI: $3.94 \pm 2.046$ and ASDASCRP: $2.75 \pm 1.05$. The mean BASFI was $4.17 \pm 2.7$

SP changes were observed in 31 patients: score $1(n=14)$, score $2(n=8)$, score 3 $(n=8)$ and score $4(n=4)$. Sex ratios $M / F$ were 2.1 and 1.65 in $G 1$ and $G 0$, respectively $(p=0.23)$. No statistically significant differences were reported between the two groups $\mathrm{G0}$ and $\mathrm{G} 1$ : mean age ( 40.48 vs. $43.45, \mathrm{p}=0.324)$, mean disease duration (11.19 vs. 14.45, $p=0.218$ ), mean BASDAI (3.8 versus $3.9, p=0.850$ ), mean ASDAS-ESR (3.09 vs. 2.55, $\mathrm{p}=0.113$ ) and mean BASFI (3.76 versus 4.96, $p=0.06$ ) respectively. In $G 1$, nine patients had hip involvement $(p=0.203)$. Enthesitis was more common in patients with SP changes $(p=0.02)$

Conclusion: In our study, the presence of enthesitis was associated with SP changes. Surprisingly, age and disease duration did not influence SP changes (1). REFERENCES:

[1] Kang Y, Ahn JM, Lee E, Lee JW, Kang HS. Active inflammatory changes around the pubic symphysis in patients with axial spondyloarthritis: Magnetic resonance imaging characteristics and association with clinical factors. Eur $\mathrm{J}$ Radiol. mars 2020;124:108802.

Disclosure of Interests: None declared.

DOI: 10.1136/annrheumdis-2021-eular.4013

\section{POS1014 \\ CENTRAL SENSITIZATION HAS MAJOR IMPACT ON QUALITY OF LIFE IN PATIENTS WITH AXIAL SPONDYLOARTHRITIS}

S. Kieskamp ${ }^{1}$, D. Paap ${ }^{1}$, M. Carbo ${ }^{1}$, F. Wink ${ }^{2}$, R. Bos ${ }^{2}$, H. Bootsma ${ }^{1}$, S. Arends ${ }^{1}$, A. Spoorenberg ${ }^{1}$ on behalf of Groningen Leeuwarden Axial Spondyloarthritis (GLAS). ${ }^{1}$ University Medical Center Groningen, Rheumatology and Clinical Immunology, Groningen, Netherlands; ${ }^{2}$ Medical Center Leeuwarden,

Rheumatology, Leeuwarden, Netherlands

Background: Maintaining optimal health-related quality of life (QoL) is the ultimate goal of treatment in axial spondyloarthritis (axSpA). Chronic pain has a large potential impact on QoL. Central sensitization (CS) may explain part of the chronic pain in axSpA. However, the role of central sensitization (CS) herein has only been studied to a limited degree and current axSpA guidelines pay little attention to identification and treatment of CS.

Objectives: To explore the relationship between CS and QoL in axSpA.

Methods: Consecutive outpatients with axSpA from the Groningen Leeuwarden Axial Spondyloarthritis (GLAS) cohort were included. CS was assessed with the Central Sensitization Inventory (CSI; 0-100), QoL with the AS Quality of Life questionnaire (ASQoL; 0-18) and disease activity with the AS Disease Activity Score (ASDAS ${ }_{\text {PRP }}$ ). A high probability of CS was defined as CSI score $\geq 40$ and active disease as ASDAS $_{\text {CRP }}$ score $\geq 2$. 1 . Patient characteristics and clinical assessments were compared between groups with CSI score $<40$ and $\geq 40$.(1) Multivariable regression analysis was conducted to investigate the relationship between CSI and ASQoL scores, correcting for potential confounders.

Results: Of the 178 axSpA patients with available CSI score, 149 completed the ASQoL. Mean age of the 178 included patients was $47.4 \pm 14.1$ years, 78 (44\%) were female, mean symptom duration was $21.4 \pm 13.6$ years and $88(52 \%)$ were using bDMARDS. Mean CSI score was $38.0 \pm 14.1$, mean ASQoL $6.0 \pm 5.3$ and mean ASDAS $2.1 \pm 1.0$. CSI score $\geq 40$ was significantly associated with higher mean ASQoL (9.7 vs. 3.3), higher mean ASDAS $_{\text {CRP }}$ (2.6 vs. 1.7), female gender $(60 \%$ vs. $29 \%)$ and more often entheseal involvement (61\% vs. $26 \%$ ) (Table 1$)$

Table 1. Selection of patient characteristics, disease activity and clinical outcome variables for patients with axSpA, divided in subgroups for CSI score with a cutoff point of 40 .

\begin{tabular}{|c|c|c|c|}
\hline Characteristics & $\begin{array}{l}\text { All patients } \\
\mathrm{n}=178\end{array}$ & $\begin{array}{c}\mathrm{CSI}<40 \\
\mathrm{n}=98(55 \%)\end{array}$ & $\begin{array}{c}C S I \geq 40 \\
n=80(45 \%)\end{array}$ \\
\hline Age (years) & $47.4 \pm 14.1$ & $48.7 \pm 15.0$ & $45.8 \pm 12.7$ \\
\hline Female & $78(44)$ & $27(29)$ & $44(60)^{*}$ \\
\hline Symptom duration (years) & $21.4 \pm 13.6$ & $21.5 \pm 13.5$ & $21.2 \pm 13.8$ \\
\hline HLA-B27+ & $133(79)$ & $70(79)$ & $54(79)$ \\
\hline Smoker & $45(27)$ & $28(32)$ & $15(23)$ \\
\hline BMI $\left(\mathrm{kg} / \mathrm{m}^{2}\right)$ & $26.7 \pm 5.0$ & $26.2 \pm 4.4$ & $27.5 \pm 5.8$ \\
\hline Completed higher education ${ }^{1}$ & $81(71)$ & $48(70)$ & $34(76)$ \\
\hline Biological use & $88(52)$ & $49(52)$ & $39(51)$ \\
\hline $\mathrm{RDCl}(0-9)$ & $0.0(0.0-1.0)$ & $0.0(0.0-1.0)$ & $0.0(0.0-1.8)$ \\
\hline Peripheral arthritis ${ }^{2}$ & $10(6)$ & $5(6)$ & $5(8)$ \\
\hline Entheseal involvement ${ }^{3}$ & $64(40)$ & $23(26)$ & $38(61)^{*}$ \\
\hline ASDAS $_{\text {CRP }}$ & $2.1 \pm 1.0$ & $1.7 \pm 0.9$ & $2.6 \pm 1.0^{\star}$ \\
\hline CRP $(\mathrm{mg} / \mathrm{ml})$ & $2.9(1.1-6.8)$ & $2.6(1.1-6.0)$ & $3.6(1.4-7.0)$ \\
\hline ASQoL $(0-18)$ & $6.0 \pm 5.3$ & $3.3 \pm 3.6$ & $9.7 \pm 4.9^{*}$ \\
\hline CSI $(0-100)$ & $38.0 \pm 14.1$ & $28.0(23-34)$ & $50.0(43.0-56.0)$ \\
\hline
\end{tabular}

Values are $\mathrm{n}(\%)$, mean \pm SD or median (IQR).1 International Standard Classification of Education (ISCED) level >4; 2Swollen Joint Count $>0$; 3Maastricht Ankylosing Spondylitis Enthesitis Score $>0$. ${ }^{*} p<0.001$. ASDASCRP: Ankylosing Spondylitis Disease Activity Score; ASQoL: Ankylosing Spondylitis Quality of Life questionnaire; CRP: C-reactive protein; CSI: Central Sensitization Inventory; RDCI: Rheumatic Disease Comorbidity Index.
Patients with low ASDAS ${ }_{\text {PRP }}(<2.1)$ and also low CSI score $(<40)$ showed good QoL (median ASQoL 1.1). Patients with low ASDAS ${ }_{C R P}$ combined with high CS score $(\geq 40)$ and patients with high ASDAS $_{\text {RP }}(\geq 2.1)$ combined with low CS score reported worse QoL (median ASQoL 5.6 and 4.1, respectively). Patients with high ASDAS ${ }_{\mathrm{CRP}}$ and also high CSI score reported the worst QoL (median ASQoL 12.0). (Figure 1).
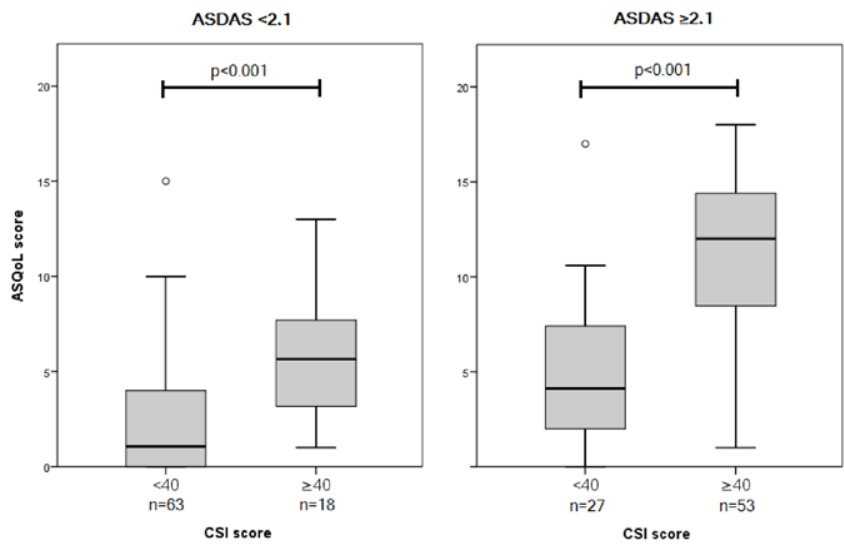

Figure 1. ASQoL score in patients with axSpA with $\mathrm{CSI}$ score $>40$ and $<40$, divided for ASDAS $_{\text {CRP }}$ (cutoff 2.1)

Additionally, in univariable analysis, the CSI score explained a large proportion of the variation of the $A S Q \circ L\left(R^{2}=0.46\right)$. This association remained significant after correction for ASDAS $_{\mathrm{CRP}}$, gender, symptom duration, entheseal involvement, smoking status, BMI category, educational level and comorbidities in multivariable analysis (CSI $\mathrm{p}<0.001)$.

Conclusion: In daily clinical practice, CS seems strongly related to patient-reported QoL in patients with long-term axSpA.

REFERENCES:

[1] Neblett R et al. J Pain. 2013;14:438-45.

Acknowledgements: The authors would like to thank all patients who participated in the GLAS cohort. Furthermore, the authors wish to acknowledge Mrs B. Burmania, Mrs. B. Hollander, Mrs. S. Katerbarg, Mrs. S. Lange, Mrs. E. Markenstein, Mrs. R. Rumph and Mrs. M. de Vries-Veldman for their contribution to clinical data collection.

Disclosure of Interests: Stan Kieskamp: None declared, Davy Paap: None declared, Marlies Carbo: None declared, Freke Wink Consultant of: Abbvie, Reinhard Bos: None declared, Hendrika Bootsma Grant/research support from: Roche, Suzanne Arends Grant/research support from: Pfizer, Anneke Spoorenberg Consultant of: Abbvie, Pfizer, MSD, UCB, Lilly, Novartis, Grant/research support from: Abbvie, Pfizer, UCB, Novartis.

DOI: 10.1136/annrheumdis-2021-eular.4035

\section{POS1015 ANTI-TNF DRUGS AND CARDIOVASCULAR EVENTS IN PATIENTS WITH SPONDYLOARTHRITIS}

C. W. S. Chan ${ }^{1}$, P. H. LI ${ }^{1}$, C. S. Lau ${ }^{1}$, H. Y. Chung ${ }^{1} .{ }^{1}$ The University of Hong Kong, Queen Mary Hospital, Hong Kong, Division of Rheumatology and Clinical Immunology, Department of Medicine, Hong Kong, Hong Kong (SAR)

Background: Cardiovascular (CVS) diseases are the leading cause of death worldwide and patients with rheumatic diseases have an increased CVS risk including stroke and myocardial infarction (MI) (1-3). CVS risk factors and CVS events are common in SpA (4). Delineating the CVS risk and the association with medications in patients with $\mathrm{SpA}$ would be useful.

Objectives: The objective of this study was to delineate the CVS risk and the association with medications in patients with SpA.

Methods: Patients with $\mathrm{SpA}$ and patients with non-specific back pain (NSBP) were identified in rheumatology and orthopedics clinics respectively. Clinica information and CVS events were retrieved. Incidence rates were calculated. Association analysis was performed to determine the CVS risk of SpA and other modifiable risk factors.

Results: A total of 5046 patients (SpA 2616 and NSBP 2430) were included from eight centers. Over 56484 person-years of follow-up, 160 strokes, $84 \mathrm{Ml}$ and 262 major adverse cardiovascular events (MACE) were identified. Hypercholesterolemia was more prevalent in SpA (SpA 34.2\%, NSBP 28.7\%, P<0.01). Crude incidence rates of stroke and $\mathrm{MI}$ were higher in SpA patients. SpA was associated with a higher risk of MACE $(\mathrm{HR} 1.66,95 \% \mathrm{Cl} 1.22-2.27, \mathrm{P}<0.01)$ and cerebrovascular events ( $\mathrm{HR} 1.42,95 \% \mathrm{Cl} 1.01-2.00, \mathrm{p}=0.04)$. The use of anti-tumor necrosis factor (TNF) drugs was associated with a reduced risk of MACE (HR $0.37,95 \% \mathrm{Cl} 0.17-0.80, \mathrm{P}=0.01)$ and cerebrovascular events (HR $0.21,95 \% \mathrm{Cl}$ $0.06-0.78, P=0.02$ ). 
Conclusion: SpA is an independent CVS risk factor. Anti-TNF drugs were associated with a reduced CVS risk in these patients.

REFERENCES:

[1] Crowson CS, Liao KP, Davis JM, 3rd, Solomon DH, Matteson EL, Knutson $\mathrm{KL}$, et al. Rheumatoid arthritis and cardiovascular disease. Am Heart J. 2013;166(4):622-8 e1.

[2] Verhoeven F, Prati C, Demougeot C, Wendling D. Cardiovascular risk in psoriatic arthritis, a narrative review. Joint Bone Spine. 2020;87(5):413-8.

[3] Liew JW, Ramiro S, Gensler LS. Cardiovascular morbidity and mortality in ankylosing spondylitis and psoriatic arthritis. Best Pract Res Clin Rheumatol. 2018;32(3):369-89.

[4] Molto A, Etcheto A, van der Heijde D, Landewe R, van den Bosch F, Bautista Molano W, et al. Prevalence of comorbidities and evaluation of their screening in spondyloarthritis: results of the international cross-sectional ASAS-COMOSPA study. Ann Rheum Dis. 2016;75(6):1016-23.

Disclosure of Interests: None declared.

DOI: 10.1136/annrheumdis-2021-eular.4133

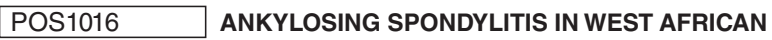 PATIENTS: A SERIES OF 37 CASES REPORTED IN TOGO}

P. Houzou ${ }^{1}$, V. E. S. Koffi-Tessio², S. Oniankitan ${ }^{3}$, K. Kakpovi ${ }^{1}$, E. Fianyo ${ }^{2}$, K. Tagbor ${ }^{2}$, O. Oniankitan ${ }^{2}$, M. Mijiyaw ${ }^{2} .{ }^{1}$ University of Kara, Rheumatology, Kara, Togo; ${ }^{2}$ University of Lomé, Rheumatology, Lomé, Togo; ${ }^{3}$ University of Lomé, Rheumatology, Kara, Togo

Background: Spondyloarthritis (SpA) is generally uncommon in sub-Saharan Africa, in part because of the rarity of HLA-B27 in this region.

Objectives: The aim of our study was to determine the epidemiological, semiological, paraclinical and therapeutic aspects of ankylosing spondylitis in rheumatology in Togo.

Methods: This was a retrospective multicenter descriptive study on the files of patients suffering from ankylosing spondylitis seen in an outpatient setting or hospitalized in one of the four Rheumatology departments of Togo in the period from January 1, 2000 to December 31, 2019. The diagnosis was essentially radio-clinical based on the modified New York criteria.

Results: In 20 years, and out of a population of 35,304 rheumatic patients, we have collected 37 cases of ankylosing spondylitis, meaning a hospital frequency of $0.10 \%$ and an annual frequency of 1.85 cases. There was clearly a male predominance with an $\mathrm{M} / \mathrm{F}$ ratio of 4.28 . The onset of the disease was on average of $29.62 \pm 10.27$ years and the diagnosis delay on average of $9.45 \pm 9.20$ years. The clinic was dominated by spinal pain in the form of chronic inflammatory cervical-dorsal-lumbar pain $(41.2 \%)$ or lumbar pain $(29.4 \%)$. Common joint injuries were those of the knees $(57.69 \%)$, ankles $(26.9 \%)$ and shoulders $(23.1 \%)$. The most frequent extra-articular manifestations were ocular with conjunctivitis $(62.5 \%)$ and uveitis $(37.5 \%)$. Due to the delayed diagnosis, significant spinal deformities including hypercyphosis, straightness and ankylosis were found; the radiography of the spine objectified syndesmophytes $(50.0 \%)$ with ankyloses and the bamboo column (23.5\%) and that of the pelvis objectified sacroiliitis at stage $3(54.6 \%)$ and at stage $4(27.3 \%)$. The HLA B27 antigen was positive in $10.8 \%$ of cases. NSAIDs and sulfasalazine were the most commonly used drugs in management, respectively in $94.3 \%$ of symptomatic treatment and $92.6 \%$ of background therapy.

Conclusion: Ankylosing spondylitis is relatively rare in Togo, affecting more men and young adults. There are no clinical or paraclinical particularity. The delay in diagnosis reflects the importance of the radiological signs. Treatment is mainly done by NSAIDs and DMRADs in particular sulfasalazine, due to their accessibility.

REFERENCES:

[1] Dean LE, Jones GT, MacDonald AG, Downham C, Sturrock RD, Macfarlane GJ. Global Prevalence of Ankylosing Spondylitis. Rheumatology (Oxford). 2014;53:650-7.

[2] Zabsonre TWJ, Sawadogo SA, Kabore F, Ilboudo A, Sougue C, Zongo E, et al. Ankylosing Spondylitis in Sub-Saharan Africa: A Series of 48 Cases Reported in Burkina Faso (West Africa). Open J Rheumatol Autoimmune Dis. 2018;8:87-92.

[3] Mijiyawa M. Ankylosing Spondylitis in Togolese Patients. Med Trop. 1993;53:185-9.

Disclosure of Interests: None declared.

DOI: 10.1136/annrheumdis-2021-eular.4199

\section{POS1017 CARDIOVASCULAR RISK IN DIFFERENT CLINICAL VARIANTS OF SPONDYLOARTHRITIS}

A. Dadalova ${ }^{1}$, E. Vasilenko ${ }^{1}$, R. Samigullina ${ }^{1}$, V. Mazurov ${ }^{1} .{ }^{1}$ North-Western State Medical University named after I.I. Mechnikov, Department of Therapy,
Rheumatology, Examination of Temporary Disability and Quality of Medical Care named after E.E.Eichwald, St. Petersburg, Russian Federation

Background: Numerous studies have shown that the life expectancy of patients with spondyloarthritis (SPA) is, on average, 5-7 years less compared to the population, and the overall mortality rate is 1.6-1.9 times higher than the population, while mortality from cardiovascular disease increases by $20-40 \%$.

Objectives: of the current study were to assess the cardiovascular risk in pts with with ankylosing spondylitis, psoriatic arthritis and psoriatic spondyloarthritis and to compare different cardiovascular risk scales in these pts.

Methods: The study included 54 patients with SpA aged 45 to 65 years. The patients were divided into 3 groups: patients with ankylosing spondylitis (AS) who meet the modified New York criteria for AS (1984) $(n=14)$, patients with psoriatic arthritis (PsA) who meet the CASPAR criteria (Classification criteria of Psoriatic Arthritis, 2006) $(n=18)$ and patients with psoriatic spondyloarthritis (PsSpA) meeting the modified New York criteria for AS and CASPAR criteria for PsA $(n=22)$.

The average age in the AS group was $55.5 \pm 6.43$ years, in the PSA group -57.4 \pm 5.76 years, in the PsSpA group $-55.0 \pm 6.45$ years. Men made up $64.3 \%$ in the AC group, $50 \%$ in the PsA group, and $49 \%$ in the PsSpA group.

Three indices of cardiovascular risk evaluation (Systematic COronary Risk Evaluation (SCORE) with increasing coefficient 1.5 for inflammatory diseases Reynolds Risk Score (RRS), and the third modification of QRESEARCH Cardiovascular Risk Algorithm (QRISK3) were calculated.

After the numerical assessment of the indicators, each patient was graded in the degree of CVR with the allocation of low, medium, high and very high degree. To stratify the degrees, an estimate of the total risk on the SCORE scale was used: with a value of less than $1 \%$, the risk was considered low, from> $1 \%$ to $5 \%$ medium or moderately increased, from $>5 \%$ to $10 \%$ - high, and $>10 \%$ - very high Results: The values of the indices were in the AS group SCORE $-3,05 \pm 2,41 \%$, RRS - 5,05 $\pm 2,67 \%$, QRISK3 - 6,68 $\pm 3,11 \%$, in pts with PSA SCORE $4,11 \pm 2,22 \%$, RRS $-5.72 \pm 2.46 \%$, QRISK3 $-7.25 \pm 2.51 \%$ and in pts with PsSpA SCORE $-4.78 \pm 2.65 \%$, RRS $-6.35 \pm 2.34 \%$, QRISK3 $-8.02 \pm 3.25 \%$.

Table 1. The number of pts corresponding to different degrees of risk depending on the used CVD risk assessment scale, $n=54$

\begin{tabular}{lccc}
\hline Degrees of risk & SCORE & RRS & QRISK3 \\
\hline Low & 9 & 2 & 0 \\
Medium & 32 & 26 & 16 \\
High & 12 & 23 & 28 \\
Very high & 1 & 3 & 10 \\
\hline
\end{tabular}

When assessing CVR using various risk assessment scales (RRS, QRISK3, SCORE), the highest values were obtained in the PsSpA group.

When comparing the results obtained, it was found that the majority of the surveyed belonging to a low degree of CVR according to SCORE ( 9 people), when evaluated using other scales, fell into the group of medium or high risk. The assessment of the risks of 10-year significant cardiovascular events in patients with SPA using the SCORE index does not coincide with the QRISK3 index data in $70.4 \%$ of cases, with the RRS data - in $42.6 \%$ of cases, and the SCORE index shows lower values of the expected risk. The highest values were obtained when assessing CVR using the scale QRISK3.

Conclusion: The highest CVR values were obtained in the PsSpA group using various risk assessment scales (RRS, QRISK3, SCORE). There was a discrepancy in the severity of CVR calculated using different rating scales in SpA patients. The largest values were obtained when using the scale QRISK3, and the smallest when calculating the CVR using the scale SCORE.

\section{REFERENCES:}

[1] Horreau C, Pouplard C, Brenaut E, Barnetche T, Misery L, Cribier B, et al. Cardiovascular morbidity and mortality in psoriasis and psoriatic arthritis: a systematic literature review. J Eur Acad Dermatol Venereol 2013;27 Suppl 3:12-29.

[2] Bengtsson K, Forsblad-d'Elia H, Lie E, et al. Are ankylosing spondylitis, psoriatic arthritis and undifferentiated spondyloarthritis associated with an increased risk of cardiovascular events? A prospective nationwide population-based cohort study. Arthritis Res Ther. 2017 May 18;19(1):102. doi: 10.1186/s13075-017-1315-z

Disclosure of Interests: None declared.

DOI: 10.1136/annrheumdis-2021-eular.4209

\section{POS1018 \\ IMPORTANCE OF LATERAL SPINE VIEW IN DXA BONE DENSITOMETRY IN PATIENTS WITH SPONDYLOARTHRITIS}

S. Miri ${ }^{1}$, H. Ferjani ${ }^{1}$, K. Maatallah ${ }^{1}$, A. Kasraoui ${ }^{1}$, D. Kaffel ${ }^{1}$, W. Hamdi ${ }^{1}$ ${ }^{1}$ Mohamed Kassab Institute of Orthopedics, Rhumatology, Manouba, Tunisia 